\title{
Stable Boron-Containing Blue-Photoluminescent Radicals
}

\author{
Zhongtao Feng,, ${ }^{\mathrm{ta}}$ Yuanyuan Chong, ${ }^{\mathrm{t}, \mathrm{b}}$ Shuxuan Tang, ${ }^{\mathrm{a}}$ Huapeng Ruan, ${ }^{\mathrm{a}}$ Yong Fang, ${ }^{\mathrm{a}}$ Yue Zhao, ${ }^{\mathrm{a}}$ \\ Jun Jiang, ${ }^{*, \mathrm{~b}}$ and Xinping Wang, \\ a State Key Laboratory of Coordination Chemistry, School of Chemistry and Chemical Engineering, Collaborative \\ Innovation Center of Advanced Microstructures, Nanjing University, Nanjing 210093, China \\ ${ }^{b}$ Hefei National Laboratory for Physical Sciences at the Microscale, CAS Center for Excellence in Nanoscience, School \\ of Chemistry and Materials Science, University of Science and Technology of China, Hefei, Anhui 230026, China
}

*E-mail: xpwang@ nju.edu.cn, jiangj1@ustc.edu.cn

t These authors contributed equally to this work.

ABSTRACT: It is highly urgent to develop synthetic strategies to make new category of stable luminescent radicals with desired emission wavelength. In this study, we have isolated two dioxoborocyclic radicals ( $\mathbf{3}$ and $\mathbf{4}$ ) by a direct synthetic route. They were characterized by UV, EPR spectroscopy and SQUID measurements. Their structures were obtained by single-crystal X-ray diffraction. Both radicals produce blue-photoluminescence ( $458 \mathrm{~nm}$ for 3 and $478 \mathrm{~nm}$ for 4 ) by radiative decay from higher excited states $\left(\mathrm{D}_{2} / \mathrm{D}_{3}\right)$ to the ground state $\left(\mathrm{D}_{0}\right)$ based on theoretical calculation, breaking Kasha rule. The work records a new kind of radical emitters and the first stable radicals with blue emission bands.

Molecules with luminescence have been extensively investigated for their applications in organic lightemitting diodes (OLEDs) and chemical sensors. ${ }^{1}$ Among them, molecules with open-shell doublet ground states recently have gained much attention as they are able to avoid quenching via the spinforbidden transition from the excited triplet to the ground state and thus provide high-efficiency electroluminescent devices. ${ }^{2}$ Furthermore, the interplay between the magnetic, electronic, and luminescent properties of organic radicals may afford multiply responsive molecular devices. ${ }^{3}$ Emissive radicals therefore have been targeted as one of the next-generation luminophores. However, in contrast with numerous conventional closed-shell luminescent molecules, neutral emissive organic radicals are restricted to cholorarylmethyl radicals, which were known in 1944 and later developed by Juliá, Nishihara, Li and others. ${ }^{2}$ In addition, the emission wavelengths of cholorarylmethyl radicals are limited to red and NIR regions. Though stable anthracene functionalized dithiadiazolyl radicals with blue emission were reported by Raw-son et al., the emission is coming from the anthracene part and the dithiadiazolyl radical part is acting as a fluorescent quencher instead. ${ }^{4}$ It is highly urgent to develop synthetic strategy to make new category of stable luminescent radicals with desired emission wavelength.

Boron-containing radicals have attracted lots of interest for applications as organic synthesis reagents, magnetic system building blocks, polymerization initiators, and chemical sensors. ${ }^{5} \mathrm{~A}$ number of fivemembered diazab-orocyclic ${ }^{6}$ and dioxoborocy-clic ${ }^{7}$ radicals recently have been prepared. Stephan et al. have obtained a series of dioxoborocyclic radicals since 2016 , by $\mathrm{H}_{2}$ activation using $\mathrm{B}\left(\mathrm{C}_{6} \mathrm{~F}_{5}\right)_{3}$ and diones (4 atm, $110^{\circ} \mathrm{C}$ ) ${ }^{6 f, 7 b, 7 c, 8}$ We speculate that modification of dioxoborocyclic radicals with donor ligands may lead to photoluminescence. Here we report two stable blue-photoluminiscent dioxoborocyclic radicals, which were prepared using a direct method under mild condition. 
Dioxoborocyclic radicals $\mathbf{3}$ and $\mathbf{4}$ were synthesized in one step from the corresponding diones ( $\mathbf{1}$ and 2) with chlorobis(perfluorophenyl)borane and potassium graphite in THF, and isolated as deep red crystals in moderate yield (Scheme 1). 3 and $\mathbf{4}$ are stable in solution and in the solid state under $\mathrm{N}_{2}$ atmosphere for several weeks. They were characterized by UV, EPR spectroscopy and SQUID measurements. Their crystal structures were determined by single-crystal X-ray diffraction.

Scheme $\mathbf{1}$ Synthesis of Radicals $\mathbf{3}$ and $\mathbf{4}$, and Photographs of THF Solutions of $\mathbf{3}$ and $\mathbf{4}$ in UV (365nm) Light.

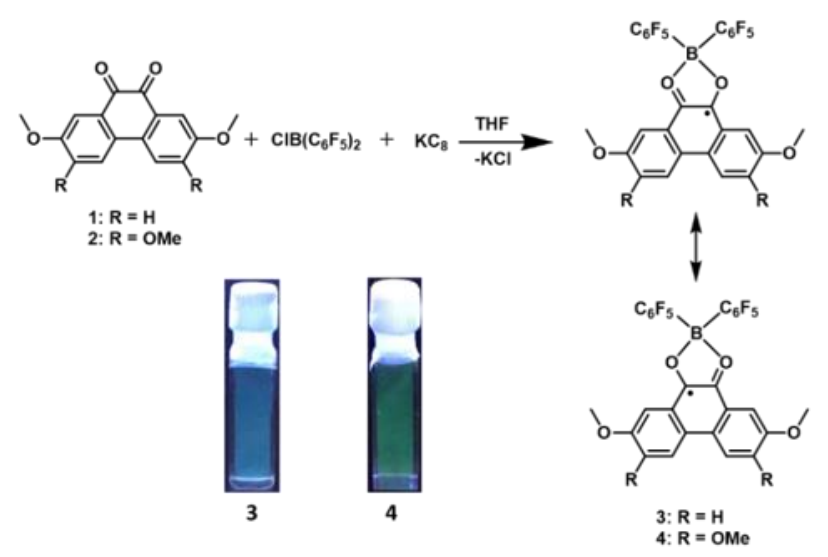

Both 3 and 4 are NMR silent. The EPR spectrum of 3 (Figures 1a and S5) displays an octet due to hyperfine coupling with ${ }^{11} \mathrm{~B}$ and ${ }^{1} \mathrm{H}$ atoms with $a_{\mathrm{B}}=3.17 \mathrm{G}, a_{\mathrm{H}}=1.91,2.47 \mathrm{G}$ by spectral simulation, suggesting the unpaired electron is delocalized over phenanthrene moiety. Similarly, the sextet of 4 (Figures $1 \mathrm{~b}$ and S6) arises from coupling with ${ }^{11} \mathrm{~B}$ atom and ${ }^{1} \mathrm{H}$ atoms $\left(a_{\mathrm{B}}=2.86 \mathrm{G}, a_{\mathrm{H}}=1.86 \mathrm{G}\right)$. As shown in Figure 2, the $\chi_{\mathrm{M}} \mathrm{T}$ at $300 \mathrm{~K}$ for both $\mathbf{3}$ and $\mathbf{4}$ is around $0.37 \mathrm{~cm}^{3} \mathrm{~K} / \mathrm{mol}$, consistent with one spin per radical $\left(\chi_{M} \mathrm{~T}=0.375 \mathrm{~cm}^{3} \mathrm{~K} / \mathrm{mol}\right.$ for $S=1 / 2$ spin system). The $\chi_{M} \mathrm{~T}$ of 3 shows an increasing susceptibility from 2 to $50 \mathrm{~K}$, indicating an intermolecular antiferromagnetic interaction, while an intermolecular ferromagnetic interaction is observed for $\mathbf{4}$ below $25 \mathrm{~K}$, but both with small coupling constants $(2 J=-44.92 \mathrm{cal} / \mathrm{mol}$ for 3 and $4.5 \mathrm{cal} / \mathrm{mol}$ for 4$)$.
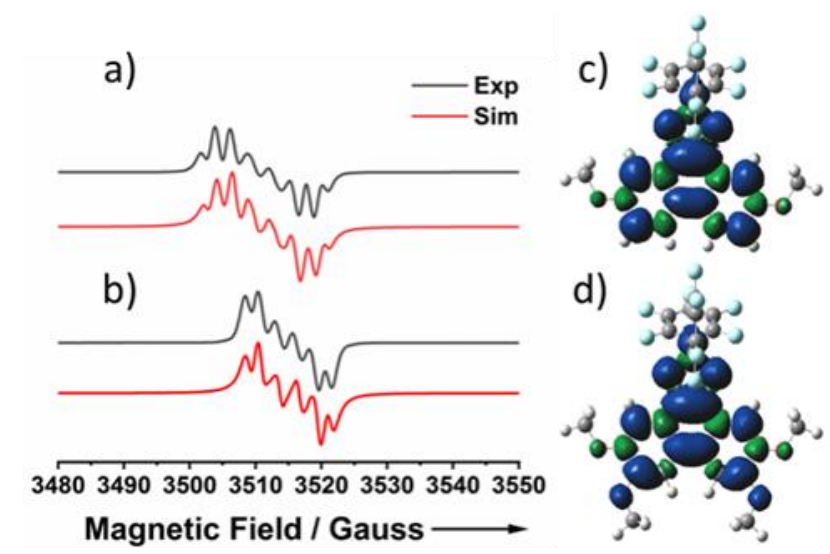

Figure 1 EPR spectra of $\mathbf{3}$ (a) and $\mathbf{4}$ (b) in THF at room temperature with sim-ulation, and spin densities of $\mathbf{3}$ (c) and $\mathbf{4}$ (d) calculated at the UB3LYP/6-31G(d) level. 


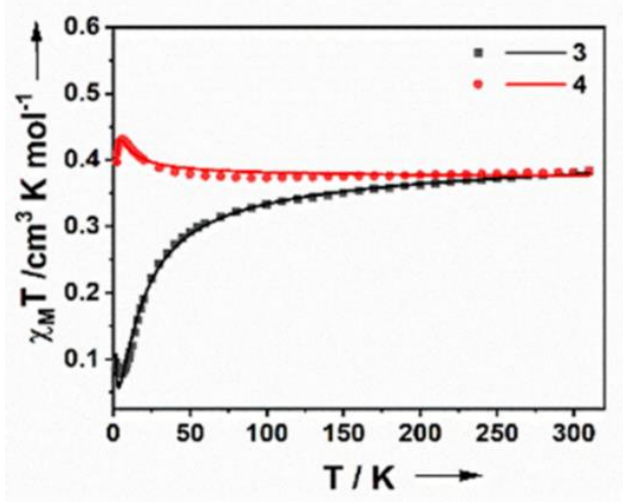

Figure $2 \chi_{\mathrm{M}}$ T versus T curve in the SQUID measurements for the powder of $\mathbf{3}$ and $\mathbf{4}$ and the fitting plot obtained with the BleaneyBowers equation. ${ }^{9}$

Crystals of $\mathbf{3}$ and $\mathbf{4}$ suitable for single crystal X-ray diffraction were grown in the concentrated toluene solution at $-20^{\circ} \mathrm{C}$. Crystal structures of parent molecules $\mathbf{1}$ and $\mathbf{2}$ were also obtained for comparison (Figures S1 and S2, Tables S3 and S4). The crystal structure of 3 exhibits a one-dimensional chain conformation with the shortest intermolecular $\mathrm{C}-\mathrm{C}$ distances of 3.395 and $3.551 \AA$ between the phenanthrenedione backbones (Figure 3c), while that of $\mathbf{4}$ shows a $\pi$-dimer structure with the shortest $\mathrm{C}-\mathrm{C}$ distance of $3.465 \AA$ between the neighbouring phenanthrenedione backbones (Figure $3 \mathrm{~d}$ ). The intermolecular $\mathrm{C}-\mathrm{C}$ distances both in $\mathbf{3}$ and $\mathbf{4}$ are close to the sum of sp2 $\mathrm{C}-\mathrm{C}$ distance $(3.40 \AA)$, indicating weak intermolecular interactions, consistent with the small coupling constants of the magnetic property. Both 3 and 4 feature a planar five-membered $\mathrm{BO} 2 \mathrm{C} 2$ ring (Figures $3 \mathrm{a}$ and $3 \mathrm{~b}$ ), with the $\mathrm{B}-\mathrm{O}$ distances of 1.549(5), 1.535(5) $\AA$ in 3 and 1.511(3), 1.531(3) $\AA$ in 4, and $\mathrm{O}-\mathrm{B}-\mathrm{O}$ angles of $101.2(3)^{\circ}$ in

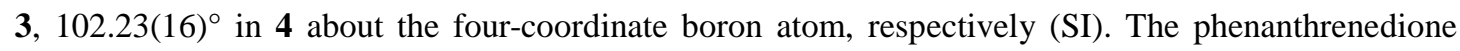
backbones are planar but $\mathrm{C} 1-\mathrm{C} 2$ bond lengths (1.407(5) $\AA$ in 3 and 1.409(3) $\AA$ in 4) are shorter than those in 1 (1.536(6) $\AA$ ) and 2 (1.533(3) $\AA$ ), while C-O bond lengths (1.332(4), 1.331(4) $\AA$ in 3 and

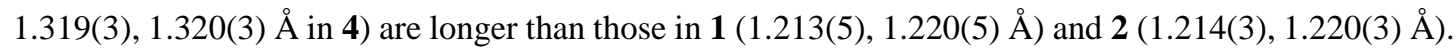
All other bond parameters of phenanthrenedione backbones basically have no changes from parent molecules to radicals. 


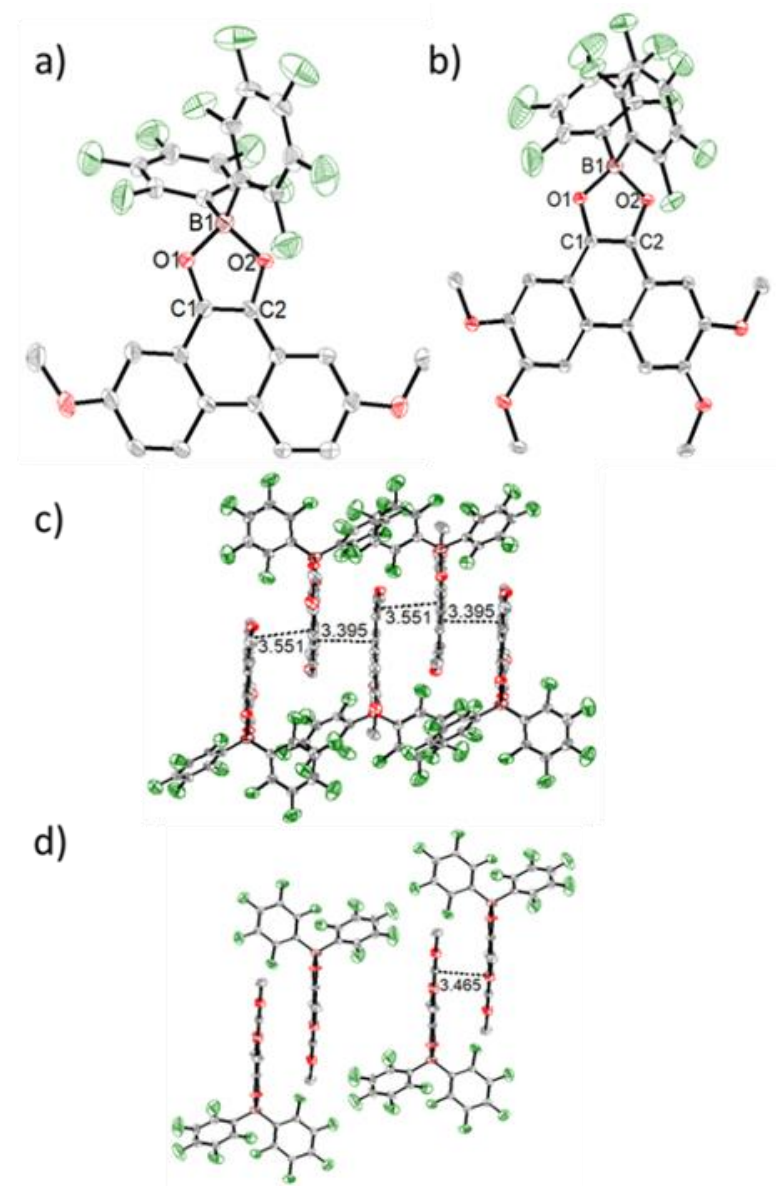

Figure 3 Thermal ellipsoid drawings (at 50\% probability) with selected bond lengths ([Å]) of molecules and crystal packings of 3 $(a, c)$ and $\mathbf{4}(b, d)$. Hydrogen atoms and solvent molecules are omitted for clarity.

The UV-Vis absorption spectrum of $\mathbf{3}$ in dilute THF solution displays an intense absorption band at $420 \mathrm{~nm}$ with an additional absorption band at $476 \mathrm{~nm}$ (Figure 4a). The absorption bands of 4 (437, 572 $\mathrm{nm}$ ) are red-shifted compared to those of $\mathbf{3}$, which can be attributed to the electron-donation of two -OMe substituent groups at the 3,6 positions of the phenanthrenedione backbone in 4 . Solution fluorescence studies on 3 and 4 revealed emissions at 458 and $478 \mathrm{~nm}$ in THF, respectively (Figure 4b). Red-shift of the emissions of $\mathbf{3}$ and $\mathbf{4}$ in DCM are observed due to the solvent polarity (Figure S9). The excited-state luminescence lifetime $(\tau)$ of $\mathbf{3}$ is estimated to be $3.9 \mathrm{~ns}$, and $7.7 \mathrm{~ns}$ for 4 (Figure 4c). The photoluminescence quantum yield (PLQY) of $\mathbf{3}$ and $\mathbf{4}$ are measured to be $0.30 \%$ and $1.03 \%$, respectively. Both radicals exhibit photochemical stability with the half-life $\left(t_{1 / 2}\right)$ of 123 min for 3 and 175 min for 4 (Figures 4d, S10 and S11). 
a)

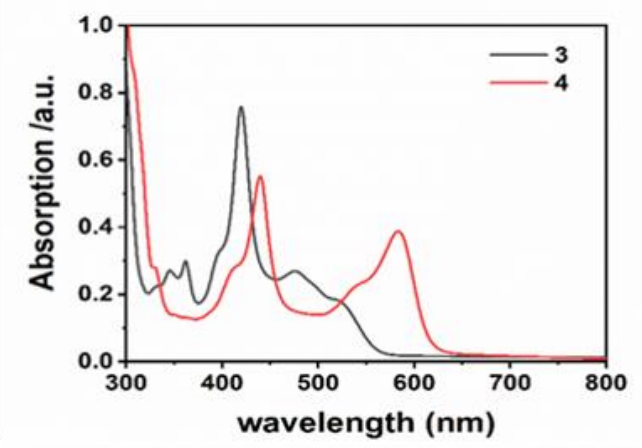

b)

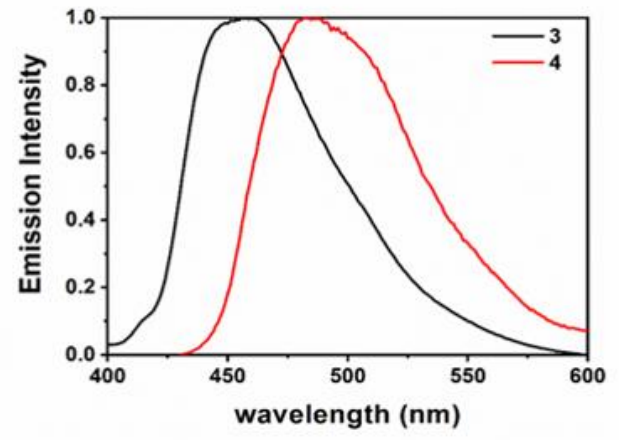

c)

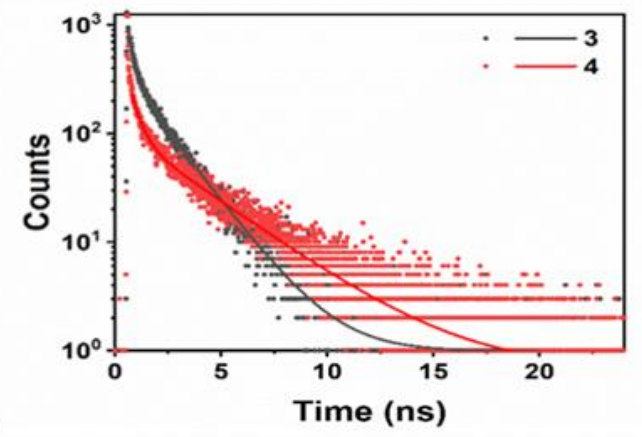

d)

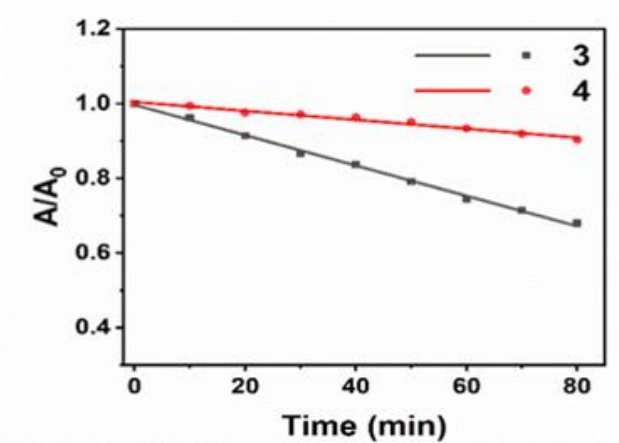

Figure 4 (a) UV/Vis absorption spectra of $\mathbf{3}$ and $\mathbf{4}$ in THF at room temperature. (b) Fluorescence spectra excited at $372 \mathrm{~nm}$ of $\mathbf{3}$ and $360 \mathrm{~nm}$ of $\mathbf{4}$ in THF at room temperature. (c) Fluorescence decay of $\mathbf{3}$ and $\mathbf{4}$ fol-lowing excitation at $365 \mathrm{~nm}$ for $\mathbf{3}$ and $\mathbf{4}$. (d) Photostability analysis of $\mathbf{3}$ and $\mathbf{4}$ under irradiation $(365 \mathrm{~nm})$ for different times. A/AO represents the ratio of absorbance before and after irradiation for the corre-sponding time.

To gain further insights into photoluminescence mechanism, quantum chemical calculations were carried out using the Gaussian 16 series of programs. ${ }^{10}$ The ground state molecular configurations(Figure S12) optimized by the unrestricted Kohn-Sham density functional theory ${ }^{11}$ (UKS-DFT) are consistent with that in the crystal structures. Due to the existence of an unpaired electron, the ground states of $\mathbf{3}$ and $\mathbf{4}$ are doublet $\left(\mathrm{D}_{0}\right)$. The spin-up unpaired electron is located on $154 \alpha$ and $170 \alpha$ orbitals in $\mathbf{3}$ and $\mathbf{4}$, respectively, namely the single electron occupied molecular orbital (SOMO), while other orbitals with 
lower energy are all occupied by two electrons, displayed in Figures 5a and 5b. The nature of electronic excited state can be revealed by time dependent DFT (TDDFT) calculation. ${ }^{12}$ As shown in Tables S5 and S6, the lowest excited state $\left(D_{1}\right)$ is mainly attributed to beta electron (spin-down) transition from HOMO to SOMO. Its oscillator strengths of both excitation $(f=0.0057$ in $3,0.0002$ in 4$)$ and emission $(f=0.0079$ in $3,0.0022$ in 4) are all close to zero, which means the "dark state" nature ${ }^{13}$ of $D_{1}$ restraining photoluminescence. Meanwhile, higher excited states have large oscillator strength, therefore valence electrons are prone to jump to higher excited state after photoexcited. However, electrons excited to $\mathrm{D}_{2}$ or other higher excited state relax to $\mathrm{D}_{1}$ state hardly. As expected, $\mathrm{D}_{2}$ and $\mathrm{D}_{3}$ excited states almost overlap owing to a minimal energy difference $(0.2 \mathrm{eV}$ in $\mathbf{3}$, almost $0 \mathrm{eV}$ in 4$)$ but a large energy gap ( $1.43 \mathrm{eV}$ in 3, $1.36 \mathrm{eV}$ in 4) between $\mathrm{D}_{2}$ and $\mathrm{D}_{1}$ even more than $1 \mathrm{eV}$, which brings about internal conversion (IC) slowly. ${ }^{14}$ In addition, $\mathrm{D}_{3}$ state are formed by the alpha electron (spin-up) transition from SOMO to LUMO in 4. Due to the opposite electronic spin orientation, the IC process from $D_{3}$ to $D_{1}$ is almost transition forbidden. At the same time, there is also the transition contribution of alpha electron in $\mathrm{D}_{2}$ and $\mathrm{D}_{3}$ states of 3. Unexpectedly, the UKS-TDDFT calculations for $\mathrm{D}_{2}$ and $\mathrm{D}_{3}$ reach consensus on fluorescence emission spectra: theoretical, $D_{2}: 430 \mathrm{~nm}, \mathrm{D}_{3}: 423 \mathrm{~nm}$, experimental, $458 \mathrm{~nm}$ in 3; theoretical, $\mathrm{D}_{2}: 503$ $\mathrm{nm}, \mathrm{D}_{3}: 502 \mathrm{~nm}$, experimental, $478 \mathrm{~nm}$ in 4 . Hence, different excited state formation upon photoexcitation, higher excited states $\left(\mathrm{D}_{2}\right.$ and $\left.\mathrm{D}_{3}\right)$ deactivate to $\mathrm{D}_{1}$ through IC process laboriously and they only return to the ground state through emission. The corresponding schematic diagrams are exhibited in Figure 5c. These theoretical results rationalize that emission obeys anti-Kasha rules. 
a)

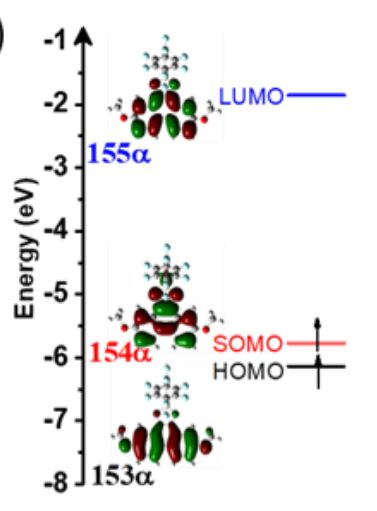

b)

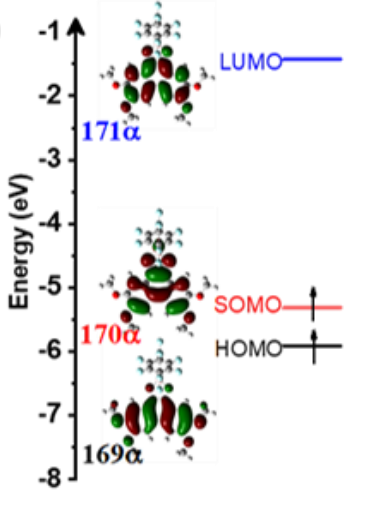

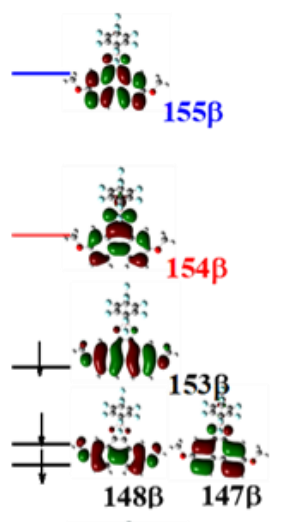

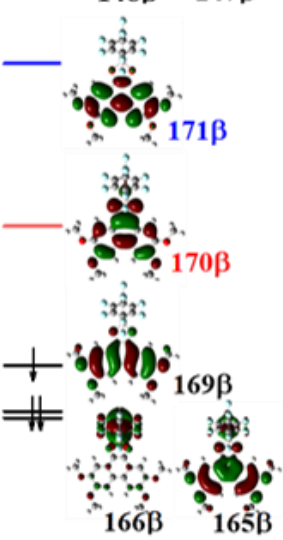

c)

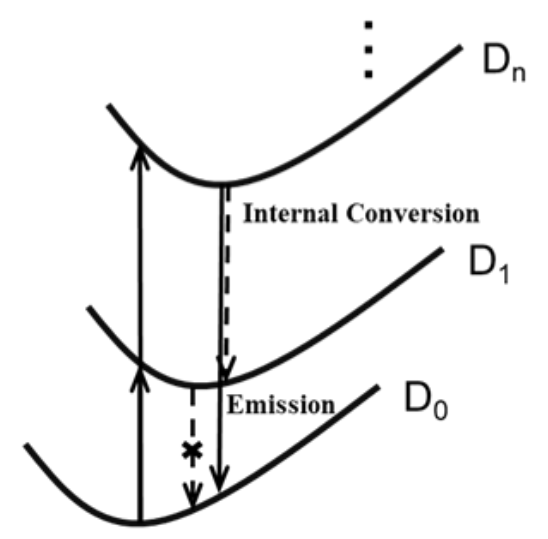

Figure 5 Quantum chemical results for the monoradical. Energy levels and wavefunctions for the ground state frontier molecular orbitals of 3 (a) and 4 (b), calculated at UB3LYP/6-31G(d,p) level of theory. (c) Schematic diagram of photophysical process after doublet excitation identified by theoretical calculations.

In summary, we have isolated two dioxoborocyclic radicals $\mathbf{3}$ and $\mathbf{4}$. They have been characterized by SQUID, EPR spectroscopy and single-crystal X-ray diffraction analysis. The structure and SQUID measurements indicates an intermolecular antiferromagnetic interaction for $\mathbf{3}$ and an intermolecular ferromagnetic interaction for $\mathbf{4}$. Both $\mathbf{3}$ and $\mathbf{4}$ are blue-photoluminescent radical emitters with anti-Kasha doublet emission. Our work provides a new kind of radical emitter species and paves the way toward blue-light radical emitters. Further work about high efficient blue-light radical emitters is continuous in our lab.

\section{Acknowledgement}

We thank the National Key R\&D Program of China (Grants 2016YFA0300404 and 2018YFA0306004 X.W.) and the National Natural Science Foundation of China (Grants 21525102 and 21690062 X.W.; 22033007 J.J.) for financial support. The calcula-tions were performed at the High-Performance 
Computing Center of Nanjing University and the Supercomputing Center of Univer-sity of Science and Technology of China.

\section{Reference}

[1] (a) Tang, C. W.; VanSlyke, S. A. Organic Electroluminescent Diodes. Appl. Phys. Lett. 1987, 51, 913-915; (b) Zhu, X. H.; Peng, J.; Cao, Y.; Roncali, J. Solution-Processable Single-Material Molecular Emitters for Organic Light-Emitting Devices. Chem. Soc. Rev. 2011, 40, 3509-3524; (c) Xu, H.; Chen, R.; Sun, Q.; Lai, W.; Su, Q.; Huang, W.; Liu, X. Recent Progress in Metal-Organic Complexes for Optoelectronic Applications. Chem. Soc. Rev. 2014, 43, 3259-3302; (d) Xu, R.; Li, Y.; Tang, J. Recent Advances in Flexible Organic Light-Emitting Diodes. J. Mater. Chem. C 2016, 4, 9116-9142.

[2] (a) Cui, Z.; Abdurahman, A.; Ai, X.; Li, F. Stable Luminescent Radicals and Radical-Based LEDs with Doublet Emission. CCS Chem. 2020, 2, 1129-1145; (b) Ai, X.; Evans, E. W.; Dong, S.; Gillett, A. J.; Guo, H.; Chen, Y.; Hele, T. J. H.; Friend, R. H.; Li, F. Efficient Radical-Based Light-Emitting Diodes with Doublet Emission. Nature 2018, 563, 536-540; (c) Abdurahman, A.; Hele, T. J. H.; Gu, Q.; Zhang, J.; Peng, Q.; Zhang, M.; Friend, R. H.; Li, F.; Evans, E. W. Understanding the Luminescent Nature of Organic Radicals for Efficient Doublet Emitters and Pure-Red Light-Emitting Diodes. Nat. Mater. 2020, 19, 1224-1229; (d) Peng, Q.; Obolda, A.; Zhang M.; Li, F. Organic Light-Emitting Diodes Using a Neutral $\pi$-Radical as Emitter: The Emission from a Doublet. Angew. Chem. Int. Ed. 2015, 127, 7197 7201; (e) Hattori, Y.; Kusamoto, T.; Nishihara, H. Luminescence, Stability, and Proton Response of an Open-Shell (3,5-Dichloro-4-pyridyl)bis(2,4,6-trichlorophenyl)methyl Radical. Angew. Chem. Int. Ed. 2014, 44, 11845-11848; (f) Hattori, Y.; Kusamoto, T.; Nishihara, H. Enhanced Luminescent Properties of an Open-Shell (3,5-Dichloro-4-pyridyl)bis(2, 4, 6-trichlorophenyl)methyl Radical by Coordination to Gold. An-gew. Chem. Int. Ed. 2015, 54, 3731-3734; (g) Liu, C.; Hamzehpoor, E.; Sakai-Otsuka, Y.; Jadhav, T.; Perepichka, D. F. Angew. Chem. Int. Ed. 2020, 59, 23030-23034.

[3] (a) Huang, Y.; Egap, E. Open-Shell Organic Semiconductors: an Emerging Class of Materials with Novel Properties. Polym. J. 2018, 50, 603-614; (b) Imran, M.; Wehrmann, C. M.; Chen, M. S. OpenShell Effects on Optoelectronic Properties: Antiambipolar Charge Transport and Anti-Kasha Doublet Emission from a N-Substituted Bisphenalenyl. J. Am. Chem. Soc. 2020, 142, 38-43.

[4] (a) Beldjoudi, Y.; Nascimento, M. A.; Cho, Y. J.; Yu, H.; Aziz, H.; Tonouchi, D.; Eguchi, K.; Matsushita, M. M.; Awaga, K.; Osorio-Roman, I.; Constantinides, C. P.; Rawson, J. M. Multi-functional Dithiadiazolyl Radicals: Fluorescence, Electrolumi-nescence, and Photoconducting Behavior in Pyren1-yl-dithiadiazolyl. J. Am. Chem. Soc. 2018, 140, 6260-6270; (b) Beldjoudi, Y.; Arauzo, A.; Campo, J.; Gavey, E. L.; Pilkington, M.; Nascimento, M. A.; Rawson, J. M. Structural, Magnetic, and Optical Studies of the Polymorphic 9' -Anthracenyl Dithiadiazolyl Radical. J. Am. Chem. Soc. 2019, 141, 6875 6889.

[5] (a) Su, Y.; Kinjo, R. Boron-Containing Radical Species. Coord. Chem. Rev. 2017, 352, 346-378; (b) Power, P. P. Persistent and Stable Radicals of the Heavier Main Group Elements and Related Species. Chem. Rev. 2003, 103, 789-810; (c) Kaim, W.; Hosmane, N. S.; Záliš, S.; Maguire, J. A.; Lipscomb, W. N. Boron Atoms as Spin Carriers in Two- and Three-Dimensional Systems. Angew. Chem. Int. Ed. 2009, 48, 5082-5091; (d) Hicks; Robin, G. Stable radicals. John Wiley \& Sons, Ltd, 2010; (e) Renaud, P. Boron in Radical Chemistry. John Wiley \& Sons, Ltd, 2012; (f) Chivers, T.; Konu, J. Stable and Per-sistent Radicals of Group 13-17 Elements. Comprehensive Inor-ganic Chemistry II (Second Edition) 2013, 1, 349-373. 
[6] (a) Hinchliffe, A.; Mair, F. S.; McInnes, E. J. L.; Pritchard, R. G.; Warren, J. E. Light Group 13 Chloride Diazadiene Complexes: Consequences of Varying Substituent Bulk. Dalton Trans. 2008, 222 233; (b) Wood, T. K.; Piers, W. E.; Keay, B. A.; Parvez, M. Spirocyclic Boronium Ions: Precursors to Persistent Neutral Radicals. Chem. Commun. 2009, 5147-5149; (c) Mansell, S. M.; Adams, C. J.; Bramham, G.; Haddow, M. F.; Kaim, W.; Norman, N. C.; McGrady, J. E.; Russell, C. A.; Udeen, S. J. Synthesis and Characterisation of the Persistent Radical [BCl2(bipy)] ${ }^{*}$ Chem. Commun. 2010, 50705072; (d) Aramaki, Y.; Omiya, H.; Yamashita, M.; Nakabayashi, K.; Ohkoshi, S.; Nozaki, K. Synthesis and Char-acterization of B-Heterocyclic $\pi$-Radical and Its Reactivity as a Boryl Radical. J. Am. Chem. Soc. 2012, 134, 19989-19992; (e) Fedushkin, I. L.; Markina, O. V.; Lukoyanov, A. N.; Morozov, A. G.; Baranov, E. V.; Maslov, M. O.; Ketkov, S. Y. Boron Complexes of Redox-Active Diimine Ligand. Dalton Trans. 2013, 7952-7961; (f) Bamford, K. L.; Longobardi, L. E.; Liu, L.; Grimme, S.; Stephan, D. W. FLP Reduction and Hydroboration of Phenanthrene o-Iminoquinones and a -Diimines. Dalton Trans. 2017, 5308-5319.

[7] (a) Pal, S. K.; Itkis, M. E.; Tham, F. S.; Reed, R. W.; Oakley, R. T. Resonating Valence-Bond Ground State in a Phenalenyl-Based Neutral Radical Conductor. Science 2005, 309, 281-284, and refs therein; (b) Longobardi, L. E.; Liu, L.; Grimme, S.; Stephan, D. W. Stable Borocyclic Radicals via Frustrated Lewis Pair Hydrogena-tions. J. Am. Chem. Soc. 2016, 138, 2500-2503; (c) Longobardi, L. E.; Zatsepin, P.; Korol, R.; Liu, L.; Grimme, S.; Stephan, D. W. Reactions of Boron-Derived Radicals with Nucleophiles. J. Am. Chem. Soc. 2017, 139, 426-435; (d) Robinson, G. H.; Wang, Y.; Xie, Y.; Wei, P.; Blair, S.; Cui, D.; Johnson, M. K.; Schaefer, H. F. Stable Boron Dithiolene Radicals. Angew. Chem. Int. Ed. 2018, 130, 7991-7994.

[8] Liu, L. L.; Stephan, D. W. Radicals Derived from Lewis Acid/base Pairs. Chem. Soc. Rev. 2019, 48, 3454-3463.

[9] Bleaney B., Bowers K. D. Anomalous paramagnetism of copper acetate. Proc. R. Soc. London, Ser. A $1952,214,451$.

[10] Frisch, M. J.; Trucks, G. W.; Schlegel, H. B.; Scuseria, G. E.; Robb, M. A.; Cheeseman, J. R.; Scalmani, G.; Barone, V.; Petersson, G. A.; Nakatsuji, H.; Li, X.; Caricato, M.; Marenich, A. V.; Bloino, J.; Janesko, B. G.; Gomperts, R.; Mennucci, B.; Hratchian, H. P.; Ortiz, J. V.; Izmaylov, A. F.; Sonnenberg, J. L.; Williams; Ding, F.; Lip-pa-rini, F.; Egidi, F.; Goings, J.; Peng, B.; Petrone, A.; Henderson, T.; Ranasinghe, D.; Zakrzewski, V. G.; Gao, J.; Rega, N.; Zheng, G.; Liang, W.; Hada, M.; Ehara, M.; Toyota, K.; Fukuda, R.; Hasegawa, J.; Ishida, M.; Nakajima, T.; Honda, Y.; Kitao, O.; Nakai, H.; Vreven, T.; Throssell, K.; Montgomery Jr., J. A.; Peralta, J. E.; Ogliaro, F.; Bearpark, M. J.; Heyd, J. J.; Brothers, E. N.; Kudin, K. N.; Staroverov, V. N.; Keith, T. A.; Kobayashi, R.; Normand, J.; Raghavachari, K.; Rendell, A. P.; Burant, J. C.; Iyengar, S. S.; Tomasi, J.; Cossi, M.; Millam, J. M.; Klene, M.; Adamo, C.; Cammi, R.; Ochterski, J. W.; Martin, R. L.; Morokuma, K.; Farkas, O.; Foresman, J. B.; Fox, D. J. Gaussian 16 Rev. C.01, Wallingford, CT, 2016.

[11] Pople, J. A.; Gill, P. M.; Handy, N. C. Spin-Unrestricted Character of Kohn-Sham Orbitals for Open-Shell Systems. Int. J. Quantum Chem. 1995, 56, 303-305.

[12] Laurent, A. D.; Jacquemin, D. TD-DFT Benchmarks: a Review. Int. J. Quantum Chem. 2013, 113, 2019-2039.

[13] Guo, H.; Jing, Y.; Yuan, X.; Ji, S.; Zhao, J.; Li, X.; Kan, Y. Highly Selective Fluorescent OFF-ON Thiol Probes Based on Dyads of BODIPY and Potent Intramolecular Electron Sink 2,4dinitrobenzenesulfonyl Subunits. Org. Biomol.Chem. 2011, 9, 3844-53.

[14] Shafikov, M. Z.; Brandl, F.; Dick, B.; Czerwieniec, R. Can Coumarins Break Kasha’s Rule? J. Phys. 
Chem. Lett. 2019, 10, 6468-6471. 